\title{
Effects of Inhaled Corticosteroids on Hospitalized Chronic Obstructive Pulmonary Disease Exacerbations: A Retrospective, Multicenter, Propensity Score-Matched Study in China
}

\section{Kang Li}

Beijing Chaoyang Hospital https://orcid.org/0000-0001-5163-8969

Ningning Tao

Beijing Hospital

Mingming Pan

Beijing Hospital

Jingjing Liu

Beijing Hospital

\section{Ting Pan}

Beijing Hospital

\section{Guoqing Fan}

Beijing Hospital

\section{Yang Cao}

Beijing Hospital

\section{Jie Zhu}

Huashan Hospital Fudan University

Ye Liu

Beijing Hospital

\section{Yanfei Guo}

Beijing Hospital

\section{Dandan Wang}

Beijing Hospital

\section{Tieying Sun ( $359219784 @ q q . c o m$ ) \\ Beijing Hospital}

\section{Research}

Keywords: chronic obstructive pulmonary disease, cardiovascular effects, corticosteroids, hospitalization, lung disease

Posted Date: November 17th, 2020

DOI: https://doi.org/10.21203/rs.3.rs-105231/v1 
License: (9) (1) This work is licensed under a Creative Commons Attribution 4.0 International License. Read Full License 


\section{Abstract}

Background: Exacerbations are important events when managing chronic obstructive pulmonary disease (COPD) because they negatively impact disease progression. Inhaled corticosteroid (ICS) usage in patients with COPD is controversial. Therefore, we reviewed the benefits and risks of regular ICS treatment in patients with COPD regarding hospitalized acute exacerbation.

Methods: This retrospective multicenter study-conducted in 18 medical centers across China-included 1,862 participants from 34 hospitals in northern China. Baseline characteristics, comorbidities, and administered medicines in the last year were matched using 1:1 propensity score-matching. We reviewed electronic patient medical records to ascertain symptoms, tests, in-hospital treatment, and prognosis. Subsequently, we reviewed computed tomography imaging results and pathogen identification tests.

Results: Patients who used ICS in the past year presented more severe respiratory symptoms during acute exacerbations of COPD but less frequent right heart failure or consciousness disturbance. More antibiotics were used during hospitalization, resulting in higher costs; however, their prognosis was not different from patients who did not use ICS. Additionally, although ICS usage could increase gram-negative bacilli in sputum smears, it did not increase the probability of pulmonary infection.

Conclusions: ICS use could protect patients from right heart failure, without detrimentally affecting prognosis during hospitalized exacerbations. Therefore, the risk of cardiovascular disease should be taken into consideration when making decisions regarding the potential administration of ICS in patients with COPD.

\section{Background}

Chronic obstructive pulmonary disease (COPD) is a heterogeneous disease that is characterized by chronic airway inflammation. Glucocorticoids are the most effective and widely used anti-inflammatory treatments and are vital in the treatment of COPD. Corticosteroid therapy improves respiratory symptoms ${ }^{[1]}$ and is associated with decreased risks of acute exacerbations ${ }^{[2,3]}$ and death; ${ }^{[4]}$ however, the use of ICS in COPD is controversial because of its side effects, including the increase in airway bacterial load ${ }^{[2]}$ and a possible increased risk of pneumonia. ${ }^{[3]}$ Nevertheless, a meta-analysis of randomized controlled trials showed that the treatment with budesonide-an inhaled corticosteroid (ICS) - did not increase the risk of pneumonia. ${ }^{[5]}$

Right heart failure is a common and serious complication in patients with COPD, which, when combined with right heart failure, can increase hospitalization rates ${ }^{[6,7]}$ and all-cause mortality. ${ }^{[7-10]}$ Recent studies showed that patients with both COPD and right heart failure may benefit from glucocorticoids. In a real-world study with a 9year follow-up, the use of either ICS alone or long-acting beta-agonist (LABA)-ICS improved overall survival in patients with COPD.${ }^{[9]}$ Another study showed that, for patients with COPD and either cardiovascular disease or a high risk of cardiovascular events, LABA-ICS could significantly improve survival when compared with LABA alone. [11]

Therefore, the influence of glucocorticoids both on the symptoms and prognosis of patients with COPD during exacerbation requires reappraisal; it is a heterogeneous disease, and, therefore, many factors-including smoking status and comorbidities-may influence the benefits as well as the risks of using corticosteroids. Therefore, in this multicenter study, we offset the influence of the patients' basic characteristics, including baseline characteristics, 
comorbidities, and medicines used during the past year, with propensity score-matching (PSM) to evaluate the benefits and the risks of using ICS in patients with COPD.

\section{Methods}

\section{Ethics approval}

The ethics committee of Beijing Hospital approved this retrospective study (2017BJYYEC-080-02) and waived the need for obtaining patients' informed consent, given the retrospective nature of the study.

\section{Participants}

This was a retrospective, multicenter study conducted in 18 medical centers across China. Participants from 34 hospitals in northern China were included in this study. In total, 1,862 participants hospitalized because of acute exacerbation of COPD between February 2015 and February 2018 were included in this study. We excluded participants without complete data on baseline characteristics, comorbidities, or administered medications during the last year. We reviewed the electronic patient medical records for information regarding symptoms, tests, hospitalization treatment, and prognosis. Subsequently, we reviewed computed tomography (CT) results and pathogen identification tests (including sputum smears, sputum cultures, and fungal cultures). An additional figure details the selection of the included patients (see Additional Fig. 1).

Right heart failure was diagnosed by cardiologists according to the following criteria of the European Society of Cardiology: isotopic ventriculography when the right ventricle ejection fraction was $\leq 35$ and /or in exercise decreased at least $5 \%$ with respect to rest value and typical signs (hepatojugular reflux, edema, and ascites). [12]

\section{Baseline characteristics and propensity score-matching}

Based on the regularity of inhaled glucocorticoid usage over the past year, patients were divided into the glucocorticoid (with-GC, $n=763$ ) and without-glucocorticoid groups (without-GC, $n=1099$ ). First, we compared the baseline characteristics, comorbidities, and medications taken during the past year between the two groups. Second, the baseline characteristics, comorbidities, and medications patients used in the past year were matched using 1:1 PSM; therefore, we obtained a matched cohort of 556 patients per group. Third, to detect the effect of PSM, we compared the above factors between the two matched groups.

The baseline characteristics included age, body mass index (BMI), sex, smoking history, acute exacerbation frequency, forced expiratory volume in $1 \mathrm{~s}$ to forced vital capacity ratio, and late-stage COPD. Matched comorbidities included asthma, pulmonary thromboembolism, interstitial lung disease, bronchiectasis, tuberculosis, coronary artery disease, coronary heart disease, diabetes, high blood pressure, cardiovascular disease, and anxiety. Medications that patients used in the last year were also matched and included short-acting beta antagonists, short-acting muscarinic antagonists, LABA, long-acting muscarinic antagonists (LAMA), theophylline, antibiotics, expectorants, and traditional Chinese medicines. Propensity scoring and 1:1 matching were conducted using the Matchlt package (version 3.0.2) for R software version 3.6.2 (https://www.r-project.org/)

\section{Symptoms and in-hospital tests}

Respiratory symptoms, cyanosis, accessory respiratory muscle involvement, unstable hemodynamics, right heart failure, and consciousness disturbance were collected by reviewing the admission records of patients. This 
analysis included the results of the first laboratory tests after admission. Respiratory failure (RF) was defined as an arterial partial pressure of oxygen to the fraction of inspired oxygen ratio $<300 \mathrm{mmHg}$. Type I RF was defined as an RF with a partial pressure of carbon dioxide $\left(\mathrm{PaCO}_{2}\right)<50 \mathrm{mmHg}$, and Type II RF was defined as an RF with $\mathrm{PaCO}_{2}>50 \mathrm{mmHg}$. Symptoms and tests were compared before and after PSM.

The results of the CT imaging and pathogen tests were first obtained after admission, before any treatment. The positions of the lung lesions were recorded. Qualified pathogen tests, including sputum smear, culture, and fungal culture, were also reviewed. Qualified pathogen tests indicated a white blood cell count $>25$ and squamous cells < 10 in the sputum. After comparing the differences between CT and pathogen tests between the two groups in the original cohort, we performed PSM separately to match baseline characteristics. Subsequently, we compared the CT imaging findings and pathogen tests between the two matched groups.

\section{Treatments and prognosis}

Treatments in the general wards, including both drug and non-drug treatments, were reviewed. Drug information included antibiotic types used at the time, the duration of antibiotics used, and whether systematic glucocorticoids were used. Non-drug treatments, including oxygen therapy and non-invasive positive-pressure ventilation, were also reviewed.

\section{Statistical analyses}

Statistical analyses were performed using the R software version 3.6.2. Categorical variables are reported either as numbers ( $n$ ) or proportions (\%), and continuous variables are expressed as either means (standard deviations) or medians (interquartile ranges). Student's $t$-test was used for comparisons of continuous variables; otherwise, the Mann-Whitney $U$ test was applied. Categorical variables were compared using the chi-squared $\left(\chi^{2}\right)$ test with Yates's correction or Fisher's exact test (when the total sample was $<40$ or the expected frequency was $<1$ ). A comparison between patients who did and did not use glucocorticoids was conducted.

\section{Results}

\section{Baseline characteristics}

The patients in the with-GC group were older and had a lower BMI. Most were men, with a history of smoking and late-stage COPD. Regarding comorbidities, patients who used glucocorticoids were more likely to have asthma, pulmonary embolism, bronchiectasis, diabetes, and hypertension. Regarding medication used in the past year, the with-GC group used more long-acting or short-acting bronchodilators but fewer antibiotics or traditional Chinese medicines. After PSM, all baseline characteristics, including comorbidities and medicines used in the past year, were matched, suggesting baseline comparability of the two groups. This is shown in an additional file (see Additional Table 1). Propensity scores, both before and after matching, in both groups are shown in an additional file (see Additional Fig. 2). 
Table 1

Symptoms of with- and without-GC groups before and after PSM

\begin{tabular}{|c|c|c|c|c|c|c|}
\hline \multirow[t]{2}{*}{ Character } & \multicolumn{3}{|l|}{ Before PSM } & \multicolumn{3}{|l|}{ After PSM } \\
\hline & $\begin{array}{l}\text { With-GC } \\
(n=763)\end{array}$ & $\begin{array}{l}\text { Without-GC } \\
(n=1099)\end{array}$ & $\begin{array}{l}\text { P- } \\
\text { value }\end{array}$ & $\begin{array}{l}\text { With-GC } \\
(n=556)\end{array}$ & $\begin{array}{l}\text { Without-GC } \\
(n=556)\end{array}$ & P-value \\
\hline Respiratory symptoms & & & $\hat{0.001}$ & & & 0.048 \\
\hline Severe $A E^{*}$ & $73(9.57 \%)$ & $55(5.00 \%)$ & & $55(9.89 \%)$ & $37(6.65 \%)$ & \\
\hline Heavy symptoms ${ }^{\ddagger}$ & $448(58.72 \%)$ & $639(58.14 \%)$ & & $323(58.09 \%)$ & $321(57.73 \%)$ & \\
\hline Less symptoms§ & $208(27.26 \%)$ & $332(30.21 \%)$ & & $156(28.06 \%)$ & $166(29.86 \%)$ & \\
\hline No symptoms ${ }^{\star \star}$ & $34(4.46 \%)$ & $73(6.64 \%)$ & & $22(3.96 \%)$ & $32(5.76 \%)$ & \\
\hline Respiratory failure (RF) & $325(42.6 \%)$ & $469(42.68 \%)$ & 0.002 & $232(41.73 \%)$ & $255(45.86 \%)$ & 0.184 \\
\hline $\begin{array}{l}\text { RF type } \\
\text { (Type1/Type2) }\end{array}$ & $71 / 240$ & 113/331 & 0.004 & $60 / 173$ & $59 / 163$ & 0.679 \\
\hline $\begin{array}{l}\text { Unstable } \\
\text { Haemodynamics }\end{array}$ & $60(7.86 \%)$ & $92(8.37 \%)$ & 0.743 & $40(7.19 \%)$ & $45(8.09 \%)$ & 0.652 \\
\hline RHF & $80(10.48 \%)$ & $164(14.92 \%)$ & 0.006 & $57(10.25 \%)$ & $85(15.29 \%)$ & 0.039 \\
\hline $\begin{array}{l}\text { Disturb of } \\
\text { consciousness }\end{array}$ & $39(5.11 \%)$ & $80(7.28 \%)$ & 0.066 & $24(4.32 \%)$ & $47(8.45 \%)$ & 0.007 \\
\hline
\end{tabular}

*Severe AE: Severe acute exacerbations, requiring invasive or non-invasive mechanical ventilation; ${ }^{\ddagger}$ Heavy symptoms: patients with increased dyspnea, increased sputum and thickened sputum at the same time; \&Less symptoms: only two of above three symptoms but must include thickened sputum; ${ }^{* *}$ No symptoms: none of above symptoms

Abbreviations: AE: acute exacerbations; GC: glucocorticoid group; PSM: propensity score-matching; RHF: right heart failure;

\section{Symptoms and comorbidities in hospitals}

As shown in both Table 1 and Fig. 1, the with-GC group had heavier respiratory symptoms (increased dyspnea and both increased and thickened sputum); however, fewer had right heart failure $(10.25 \% \mathrm{vs} .15 .29 \%, P=0.039)$ or consciousness disturbance ( $4.32 \%$ vs. $8.45 \%, P=0.007)$. Although the with-GC group had a lower rate of RF before PSM (42.60\% vs. $42.68 \%, P=0.002$, respectively), there was no difference between the two groups after matching (41.73\% vs. $45.86 \%, P=0.184)$.

\section{Computed tomography and pathogen identification tests}

As shown both in Table 2 and Fig. 2, after PSM, lung CT imaging showed that fewer patients in the with-GC group had new shadows in the right upper, right lower, and left upper lobes $(11.01 \%$ vs. $16.3 \%, P=0.026 ; 10.79 \%$ vs. $15.64 \%, P=0.040 ; 10.57 \%$ vs. $17.40 \%, P=0.004$, respectively). 
Table 2

Computed tomography imaging of with- and without-GC groups before and after PSM

\begin{tabular}{|c|c|c|c|c|c|c|}
\hline \multirow[t]{2}{*}{ Character } & \multicolumn{3}{|l|}{ Before PSM } & \multicolumn{3}{|l|}{ After PSM } \\
\hline & With GC & Without GC & P-value & With GC & Without GC & P-value \\
\hline Lung CT & $(n=631)$ & $(n=918)$ & & $(n=455)$ & $(n=455)$ & \\
\hline New lesion in CT & $257(40.73 \%)$ & $471(51.31 \%)$ & $<0.001$ & 188(41.41\%) & $217(47.8 \%)$ & 0.061 \\
\hline Right up & $66(10.87 \%)$ & $142(16.34 \%)$ & 0.004 & $50(11.01 \%)$ & 74(16.3\%) & 0.026 \\
\hline Right mid & $60(9.88 \%)$ & 133(15.3\%) & 0.003 & $45(9.91 \%)$ & $46(10.13 \%)$ & 1 \\
\hline Right down & 74(12.19\%) & $128(14.71 \%)$ & 0.190 & $49(10.79 \%)$ & $71(15.64 \%)$ & 0.040 \\
\hline Left up & $70(11.53 \%)$ & $138(15.88 \%)$ & 0.022 & $48(10.57 \%)$ & 79(17.4\%) & 0.004 \\
\hline Left down & $102(17.14 \%)$ & $139(16.24 \%)$ & 0.701 & $74(16.3 \%)$ & $69(15.2 \%)$ & 0.716 \\
\hline
\end{tabular}

Finally, we reviewed qualified pathogen identification tests, which included sputum smear, sputum culture, and fungal culture. Table 3 and Fig. 2 show that the with-GC group had more positive sputum smear tests $(79.19 \%$ vs. $64.43 \%, P=0.007$ ) but less negative sputum cultures and fungal cultures. 
Table 3

Pathogen tests of with- and without-GC groups before and after PSM

\begin{tabular}{|c|c|c|c|c|c|c|}
\hline \multirow[t]{2}{*}{ Character } & \multicolumn{3}{|l|}{ Before PSM } & \multicolumn{3}{|l|}{ After PSM } \\
\hline & With GC & Without GC & P-value & With GC & Without GC & P-value \\
\hline Sputum smear & $(n=228)$ & $(n=247)$ & & $(n=152)$ & $(n=152)$ & \\
\hline None & $47(39.83 \%)$ & $99(52.94 \%)$ & 0.034 & $31(20.81 \%)$ & $53(35.57 \%)$ & 0.007 \\
\hline G + coccus & $138(60.53 \%)$ & $117(47.56 \%)$ & 0.006 & $86(56.58 \%)$ & $77(50.66 \%)$ & 0.358 \\
\hline G + bacilli & $34(15.25 \%)$ & $24(10.13 \%)$ & 0.130 & $26(17.11 \%)$ & 17(11.18\%) & 0.188 \\
\hline G- bacilli & $98(43.95 \%)$ & 81(34.18\%) & 0.040 & $70(46.05 \%)$ & $51(33.55 \%)$ & 0.035 \\
\hline G- coccus & $31(13.9 \%)$ & $23(9.7 \%)$ & 0.210 & $20(13.16 \%)$ & $14(9.21 \%)$ & 0.363 \\
\hline Spore & $15(6.25 \%)$ & 23(9.02\%) & 0.323 & $12(7.89 \%)$ & $14(9.21 \%)$ & 0.838 \\
\hline Hypha & $11(4.58 \%)$ & $17(6.67 \%)$ & 0.419 & $9(5.92 \%)$ & $9(5.92 \%)$ & 1 \\
\hline Sputum culture & $(n=189)$ & $(n=285)$ & & $(n=120)$ & $(n=120)$ & \\
\hline G + coccus & $18(10.06 \%)$ & $10(3.58 \%)$ & 0.009 & $12(9.92 \%)$ & $9(7.44 \%)$ & 0.648 \\
\hline G + bacilli & $1(0.58 \%)$ & $1(0.36 \%)$ & -- & -- & -- & -- \\
\hline G- bacilli & $20(11.11 \%)$ & $20(7.09 \%)$ & 0.184 & $12(9.92 \%)$ & $11(9.09 \%)$ & 1 \\
\hline G- coccus & $6(3.47 \%)$ & $5(1.82 \%)$ & 0.432 & $3(2.48 \%)$ & $4(3.31 \%)$ & 1 \\
\hline Fungi culture & $(n=163)$ & $(n=198)$ & & $(n=107)$ & $(n=107)$ & \\
\hline Candida & $28(17.18 \%)$ & $24(12.12 \%)$ & 0.226 & $14(13.08 \%)$ & $18(16.82 \%)$ & 0.565 \\
\hline Aspergillus & $8(4.91 \%)$ & $3(1.52 \%)$ & 0.121 & $7(6.54 \%)$ & $3(2.8 \%)$ & 0.331 \\
\hline \multicolumn{7}{|c|}{ Abbreviations: GC: glucocorticoid group; G+: gram-positive; G-: gram-negative. } \\
\hline
\end{tabular}

\section{Treatment and prognosis}

The with-GC group used more types of antibiotics and were more likely to use systematic glucocorticoids (58.63\% vs. $40.65 \%, P<0.001$, respectively) in general wards. For non-medical support, more patients in the with-GC group underwent non-invasive positive-pressure ventilation therapy (19.6\% vs. $14.63 \%, P=0.047)$. Although the costs of the with-GC group were greater $(\$ 1,663.90$ vs. $\$ 1,251.71, P<0.001)$, there was no difference in the rate of intensive care unit transfer or the prognosis between the two groups (Table 4). 
Table 4

Treatments and prognosis

\begin{tabular}{|c|c|c|c|c|c|c|}
\hline \multirow[t]{2}{*}{ Character } & \multicolumn{3}{|l|}{ Before PSM } & \multicolumn{3}{|l|}{ After PSM } \\
\hline & $\begin{array}{l}\text { With GC } \\
(n=763)\end{array}$ & $\begin{array}{l}\text { Without GC } \\
(n=1099)\end{array}$ & $\begin{array}{l}\mathrm{P} \text { - } \\
\text { value }\end{array}$ & $\begin{array}{l}\text { With GC } \\
(n=556)\end{array}$ & $\begin{array}{l}\text { Without GC } \\
(n=556)\end{array}$ & P-value \\
\hline \multicolumn{7}{|l|}{$\begin{array}{l}\text { Treatment } \\
\text { in wards }\end{array}$} \\
\hline $\begin{array}{l}\text { Antibiotic } \\
\text { kinds }\end{array}$ & $1.3 \pm 0.5$ & $1.1 \pm 0.5$ & $\begin{array}{l}<.001 \\
0.00\end{array}$ & $1.2 \pm 0.4$ & $1.1 \pm 0.5$ & 0.035 \\
\hline $\begin{array}{l}\text { Antibiotic } \\
\text { days }\end{array}$ & $8(6 \sim 11)$ & $7(6 \sim 10)$ & $\begin{array}{l}<.001 \\
0.00\end{array}$ & $8(6 \sim 10)$ & $8(6 \sim 10)$ & 0.840 \\
\hline $\begin{array}{l}\text { Systematic } \\
\text { GC }\end{array}$ & $445(58.32 \%)$ & $376(34.21 \%)$ & $\begin{array}{l}<.001 \\
0.00\end{array}$ & $326(58.63 \%)$ & $226(40.65 \%)$ & $<0.001$ \\
\hline $\begin{array}{l}\text { Oxygen } \\
\text { therapy }\end{array}$ & $591(77.46 \%)$ & 792(72.07\%) & 0.011 & $433(77.88 \%)$ & $430(77.34 \%)$ & 0.886 \\
\hline NIPPV & $153(20.05 \%)$ & $114(10.37 \%)$ & $\begin{array}{l}<.001 \\
0.00\end{array}$ & $109(19.6 \%)$ & $83(14.93 \%)$ & 0.047 \\
\hline $\begin{array}{l}\text { Transfer to } \\
\text { ICU }\end{array}$ & $25(3.28 \%)$ & $29(2.64 \%)$ & 0.541 & $19(3.42 \%)$ & $14(2.52 \%)$ & 0.480 \\
\hline Prognosis & & & 0.101 & & & 0.063 \\
\hline Improved & $697(91.35 \%)$ & $982(89.35 \%)$ & & $521(93.71 \%)$ & $492(88.49 \%)$ & \\
\hline $\begin{array}{l}\text { Community } \\
\text { hospital }\end{array}$ & $16(2.1 \%)$ & $45(4.09 \%)$ & & $9(1.62 \%)$ & $18(3.24 \%)$ & \\
\hline Died & $14(1.83 \%)$ & $17(1.55 \%)$ & & $7(1.26 \%)$ & $13(2.34 \%)$ & \\
\hline Others & $36(4.72 \%)$ & $55(5.00 \%)$ & & $19(3.42 \%)$ & $33(5.94 \%)$ & \\
\hline Cost & $\begin{array}{l}\$ 1758.4 \\
(\$ 1142.24 \sim \\
\$ 2732.20)\end{array}$ & $\begin{array}{l}\$ 1083.7(\$ 698.71 \\
\sim \$ 1753.55)\end{array}$ & $\begin{array}{l}<.001 \\
0.00\end{array}$ & $\begin{array}{l}\$ 1663.9(\$ 1109.0 \\
\sim \$ 2506.3)\end{array}$ & $\begin{array}{l}\$ 1251.7 \\
(\$ 811.6 \sim 2022.5)\end{array}$ & $<0.001$ \\
\hline Days & $11(8 \sim 16)$ & $9(7 \sim 13)$ & $\hat{0} .001$ & $11(8 \sim 15)$ & $10(7 \sim 14)$ & 0.737 \\
\hline
\end{tabular}

Abbreviations: GC: glucocorticoid group; ICU: intensive care unit; NIPPV: non-invasive positive-pressure ventilation; PSM: propensity score-matching.

\section{Discussion}

In this study, we observed the effect of ICS on the symptoms, treatment, and prognosis of patients with COPD during hospitalization. Our study demonstrated that patients who had used ICS in the past year had more severe respiratory symptoms but were less likely to have right heart failure on admission. Moreover, although ICS could increase gram-negative bacilli in sputum smears, they did not show new shadows in the lung, which indicated that ICS might not increase the risk of pneumonia. Moreover, ICS did not detrimentally affect prognosis, thus indicating ICS's suitability for patients either with right heart failure or a high risk of heart disease. 
We showed that, although patients using glucocorticoids had more severe respiratory symptoms upon admission, they had less right heart failure, both before and after PSM, which was consistent with previous studies. In a clinical trial, ${ }^{[13]}$ the use of LABA-ICS combinations over 3 years was associated with a decrease in mortality that approached statistical significance (hazard ratio $=0.825, P=0.052$ ). In a real-world study with a 9-year follow-up, patients with a COPD-heart failure overlap could improve overall survival either by using ICS alone or LABA-ICS. ${ }^{[9]}$ Moreover, for patients with COPD with cardiovascular disease or a high risk of cardiovascular events, LABA-ICS could significantly improve survival when compared with LABA alone. ${ }^{[11]}$ Regarding patients with COPD with heart failure, LABA-ICS combination showed the most powerful protective effect: the use of LABA-ICS combinations was associated with a lower risk of death than LABA ${ }^{[14]}$ or ICS alone. ${ }^{[15]}$ Moreover, ICS/LABA treatment can reduce the severity of ST-elevation myocardial infarction in patients with COPD. ${ }^{16]}$ This study indicated that the use of ICS could increase the abundance of sputum flora, which is in line with the findings of previous studies; however, we showed that newly emerged lung shadows on CT scan decreased in the with-GC group. One possible explanation is that ICS can increase colonizing bacteria but does not necessarily cause pneumonia. To date, most studies have shown that ICS increases the risk of pneumonia. Some studies have also indicated that consequences are different for different types of glucocorticoids ${ }^{[5,17]}$ and vary according to the patient's eosinophil levels. Fluticasone-not budesonide therapy-was associated with an increased risk of pneumonia. ${ }^{[5]}$ In addition, both medium and low doses of budesonide treatment did not increase the risk of pneumonia. ${ }^{[5]}$ In addition, new lung shadows do not necessarily indicate pneumonia. Previous studies have confirmed that ICS may reduce the risk of COPD complicated by lung cancer. ${ }^{[18-21]}$ In addition, in COPD with high eosinophil levels, glucocorticoids increased the bacterial load compared with COPD with low eosinophil levels. ${ }^{[2]}$ In this study, eosinophils were not stratified and patients who used ICS may have had higher baseline eosinophil counts, which may explain the difference in findings between this and previous studies. Moreover, this study showed patients who did not use ICS last year were more likely to use traditional Chinese medicine and antibiotics instead of bronchodilators, thus suggesting that patients who used ICS last year were more likely to receive standardized treatments.

This study has some limitations. It was largely limited by its retrospective nature and its inherently biased sample population. Moreover, the patients who used ICS often used LABA and/or LAMA concurrently, while those who did not use glucocorticoids often used traditional Chinese medicine for treatment and usually used more antibiotics than those who only used ICS. We attempted to address differences in baseline characteristics, including comorbidities and medications used in the past year by performing 1:1 PSM.

\section{Conclusions}

Our study indicated that ICS use could protect patients from right heart failure, without detrimentally affecting prognosis during hospitalized exacerbations. Therefore, the use of ICS should be considered in patients with high cardiovascular disease risk.

\section{List Of Abbreviations}

COPD: chronic obstructive pulmonary disease

CT: computed tomography

GC: glucocorticoid 
ICS: inhaled corticosteroid

LABA: long-acting beta-agonist

LAMA: long-acting muscarinic antagonist

$\mathrm{PaCO}_{2}$ : partial pressure of carbon dioxide

PSM: propensity score-matching

RF: respiratory failure

\section{Declarations}

\section{Ethics approval and consent to participate}

The ethics committee of Beijing Hospital approved this retrospective study (2017BJYYEC-080-02) and waived the need for obtaining patients' informed consent, given the retrospective nature of the study.

\section{Consent for publication}

Not applicable.

\section{Competing interests}

All authors report no conflicts of interest in this work.

\section{Funding}

This work was supported by the National Key Research and Development Program of China (Project No. 2016 YFC1304601.

\section{Authors' contributions}

Data curation: KL, NT, JL, TP, GF, YC, JZ, YL, JF, HL, and TS. Formal analysis: KL and NT. Methodology: MP, YG, and DW. Validation: TS. Writing-original draft: KL, NT

\section{Acknowledgements}

We would like to thank Editage (www.editage.cn) for English language editing.

\section{References}

1. Lung Health Study Research Group, Wise R, Connett J, Weinmann G, Scanlon P, Skeans M. Effect of inhaled triamcinolone on the decline in pulmonary function in chronic obstructive pulmonary disease. N Engl J Med. 2000;343:1902-9.

2. Contoli M, Pauletti A, Rossi MR, Spanevello A, Casolari P, Marcelini A, et al. Long-term effects of inhaled corticosteroids on sputum bacterial and viral loads in COPD. Eur Respir J. 2017;50:1700451. 
3. Nici L, Mammen MJ, Charbek E, Alexander PE, Au DH, Boyd CM, et al. Pharmacologic management of chronic obstructive pulmonary disease. An official American thoracic society clinical practice guideline. Am J Respir Crit Care Med. 2020;201:e56-e69.

4. Ellingsen J, Johansson G, Larsson K, Lisspers K, Malinvoschi A, Stallberg B, et al. Impact of comorbidities and commonly used drugs on mortality in COPD - real-world data from a primary care setting. Int J Chron Obstruct Pulmon Dis. 2020;15:235-45.

5. Yang M, Du Y, Chen H, Jiang D, Xu Z. Inhaled corticosteroids and risk of pneumonia in patients with chronic obstructive pulmonary disease: a meta-analysis of randomized controlled trials. Int Immunopharmacol. 2019;77:105950.

6. Alqahtani J, Njoku C, Bereznicki B, Wimmer BC, Peterson GM, Kinsman L, et al. Risk factors for all-cause hospital readmission following exacerbation of COPD: a systematic review and meta-analysis. Eur Respir J. 2020;29:190166.

7. Axson EL, Ragutheeswaran R, Sundaram V, Bloom CL, Bottle A, Cowie MR, et al. Hospitalisation and mortality in patients with comorbid COPD and heart failure: a systematic review and meta-analysis. Respir Res. 2020:21:54.

8. Axson EL, Sundaram V, Bloom C, Bottle A, Cowie MR, Quint J. Temporal trends in the incidence of heart failure among patients with chronic obstructive pulmonary disease and its association with mortality. Ann Am Thorac Soc. 2020;17:939-48.

9. Su VY, Yang YH, Perng DW, Tsai YH, Chou KT, Su KC, et al. Real-world effectiveness of medications on survival in patients with COPD-heart failure overlap. Aging. 2019;11:3650-67.

10. Ellingsen J, Johansson G, Larsson K, Lisspers K, Malinovschi A, Stallberg B, et al. Impact of comorbidities and commonly used drugs on mortality in COPD - real-world data from a primary care setting. Int J Chron Obstruct Pulmon Dis. 2020;15:235-45.

11. Patel HC, Hayward C, Patel KS, Claggett B, Vazir A, Cowie MR, et al. Impact on survival of combination inhalers in patients with COPD at high risk of cardiovascular events. Int J Cardiol. 2020;300:237-44.

12. McMurray JJ, Adamopoulos S, Anker SD, Auricchio A, Bohm M, Dickstein K, et al. ESC guidelines for the diagnosis and treatment of acute and chronic heart failure 2012: the Task Force for the Diagnosis and Treatment of Acute and Chronic Heart Failure 2012 of the European Society of Cardiology. Developed in collaboration with the Heart Failure Association (HFA) of the ESC. Eur J Heart Fail. 2012;14:803-69.

13. Calverley PMA, Anderson JA, Celli B, Ferguson GT, Jenkins C, Jones PW, et al. Salmeterol and fluticasone propionate and survival in chronic obstructive pulmonary disease. N Engl J Med. 2007;356:775-89.

14. Gershon AS, Campitelli MA, Croxford R, Stanbrook MB, To T, Upshur R, et al. Combination long-acting $\beta$ agonists and inhaled corticosteroids compared with long-acting $\beta$-agonists alone in older adults with chronic obstructive pulmonary disease. JAMA. 2014;312:1114-21.

15. Nannini LJ, Poole P, Milan SJ, Kesterton A. Combined corticosteroid and long-acting beta (2)-agonist in one inhaler versus inhaled corticosteroids alone for chronic obstructive pulmonary disease. Cochrane Database Syst Rev. 2013;CD006826.

16. Contoli M, Campo G, Pavasini R, Marchi I, Pauletti A, Balla C, et al. Inhaled corticosteroid/long-acting bronchodilator treatment mitigates STEMI clinical presentation in COPD patients. Eur J Intern Med. 2018;47:82-6. 
17. Chang TY, Chien JY, Wu CH, Dong YH, Lin FJ. Comparative safety and effectiveness of inhaled corticosteroid and long-acting $\beta$-agonist combinations in patients with COPD. Chest. 2020;157:1117-29.

18. Raymakers AJN, Sadatsafavi M, Sin DD, FitzGerald JM, Marra CA, Lynd LD. Inhaled corticosteroids and the risk of lung cancer in COPD: a population-based cohort study. Eur Respir J. 2019;53:1801257.

19. Lee YM, Kim SJ, Lee JH, Ha E. Inhaled corticosteroids in COPD and the risk of lung cancer. Int J Cancer. 2018;143:2311-8.

20. Raymakers AJN, McCormick N, Marra CA, Fitzgerald JM, Sin D, Lynd LD. Do inhaled corticosteroids protect against lung cancer in patients with COPD? A systematic review. Respirology. 2017;22:61-70.

21. Liu SF, Kuo HC, Lin MC, Ho SC, Tu ML, Chen YM, et al. Inhaled corticosteroids have a protective effect against lung cancer in female patients with chronic obstructive pulmonary disease: a nationwide population-based cohort study. Oncotarget. 2017;8:29711-21.

\section{Figures}

Respiratory Symptoms

- Severe $\mathrm{AE}$

- Heavy symptom

Less symptom

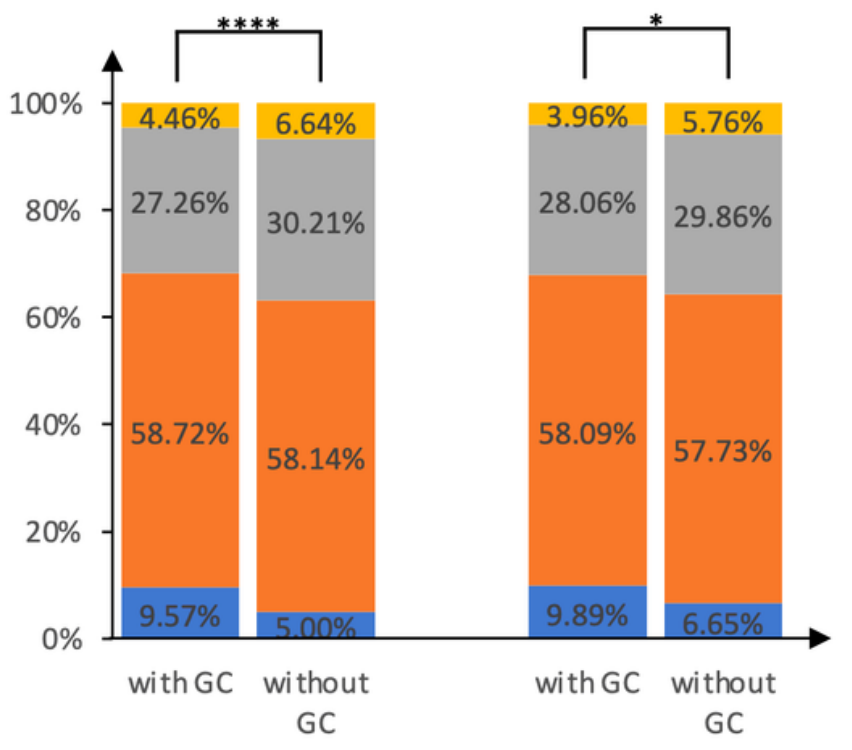

Before PSM

After PSM
Right Heart Failure

with RHF without RHF

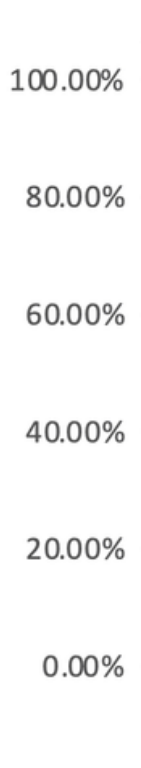

GC

Before PSM

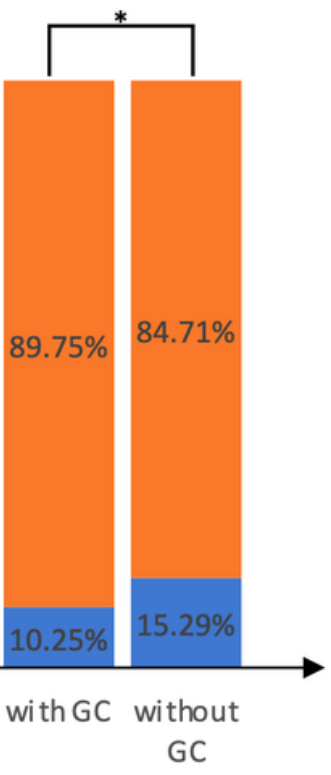

After PSM

\section{Figure 1}

Patients using glucocorticoids have severe respiratory symptoms but less right heart failure. * $p<0 . .5$, ${ }^{* *} \mathrm{p}<0.01,{ }^{* \star *} \mathrm{p}<0.001$ 
Pathogen Tests

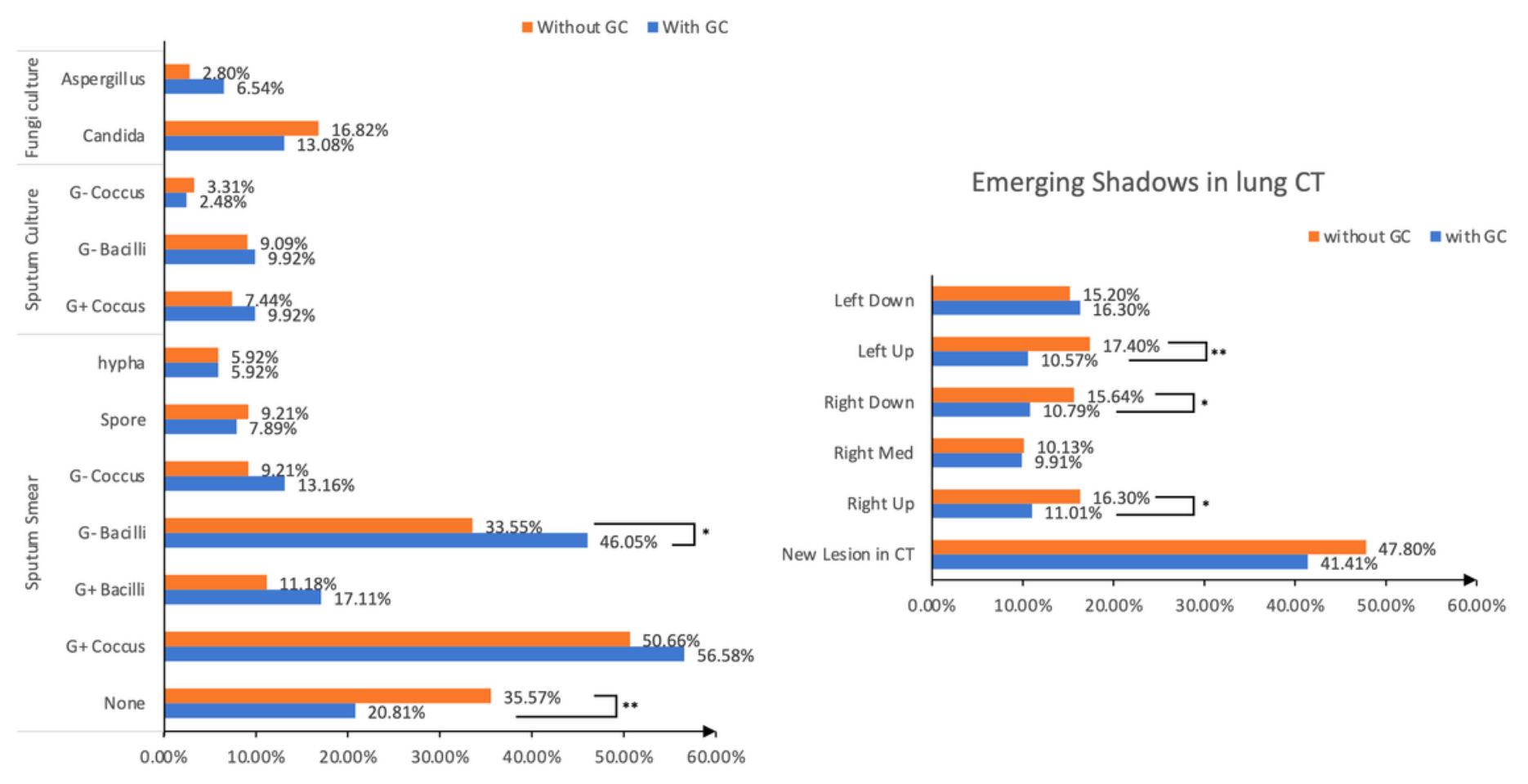

\section{Figure 2}

Pathogen tests and CT scan results in two groups. ${ }^{*} p<0.05,{ }^{* *} p<0.01$

\section{Supplementary Files}

This is a list of supplementary files associated with this preprint. Click to download.

- renamede490f.png

- supplementfigure1.pdf

- supplementtable1.pdf 